\title{
РАЗРАБОТКА ПОДХОДА К ПОВЫШЕНИЮ ЭФФЕКТИВНОСТИ УПРАВЛЕНИЯ МУНИЦИПАЛЬНЫМ ИМУЩЕСТВОМ
}

\author{
(C) 2019 Лобкова Елена Валерьевна \\ кандидат экономических наук, доцент кафедры социально-экономического планирования \\ Сибирский федеральный университет, Россия, Красноярск \\ E-mail: elenavalerin@yandex.ru
}

\begin{abstract}
Существующие проблемы управления муниципальным имуществом существенно ограничивают возможности решения задач территорий в социальной сфере и экономике. Эффективность процесса управления объектами собственности исследуется и обсуждается многими авторами. На текущий момент муниципалитеты демонстрируют низкий уровень эффективности использования потенциала имущества, принадлежащего им на правах собственности. Актуальным направлением исследования является разработка комплексного подхода к оценке результативности и эффективности управления объектами собственности муниципалитетов. Такой подход призван стать основой выработки мероприятий по совершенствованию системы управления муниципальным имуществом. Автором предложена система показателей - индикаторов важнейших проблем управления объектами собственности территорий. Разработан подход к построению оптимальной структуры имущества муниципального образования, максимизирующий совокупный доход от управления объектами. Показано применение указанного подхода на примере одного из городов при решении задачи выбора объектов недвижимости, подлежащих предоставлению в аренду и продаже в прогнозный период времени.
\end{abstract}

Ключевые слова: муниципальная собственность, имущество муниципального образования, эффективность системы управления, местный бюджет.

Муниципальная собственность как неотъемлемая часть функционирования муниципального образования является важным источником самостоятельных доходов местного бюджета и экономической основой муниципальной власти, призванной обеспечить основные потребности населения муниципального образования. Наличие и эффективное использование муниципального имущества является необходимой предпосылкой реализации основ местного самоуправления и развития муниципального образования как социально-экономического комплекса $[8,11,16,20]$.

На сегодняшний день многие муниципальные образования не способны справляться со стоящими перед ними социально-экономическими проблемами путем расходования собственных средств бюджета по причине действия несбалансированной и неэффективной системы управления объектами земельно-имущественного комплекса [5]. Существующие системы управления объектами муниципальной собственности включают критерии, подходы и методы оценки эффективности, не позволяющие адекватно анализировать процесс управления объектами и принимать решения [17, 18].
Вопросам и проблемам управления муниципальным имуществом посвящены труды многих авторов.

С.А. Труфанова предлагает внедрение модели стоимостного управления объектами недвижимости муниципального фонда, обосновывая эффективность такого подхода [15].

А.Р.Загриев с своей работе анализирует детерминанты повышения эффективности управления муниципальным имуществом и предлагает применение инструментов проектного менеджмента для решения задач управления имуществом территорий [6].

Многие авторы видят в концессионном соглашении эффективный способ решения проблем управления и использования объектов муниципального имущества [7, 14, 19].

А.С.Попов и Е.В. Гандзюк анализируют зарубежный опыт управления имуществом муниципальных образований и опыт бизнеса в управлении активами. На основании этого разрабатывают классификацию активов и критерии управления ими [13].

Авторы У.Р. Мусин, И.В. Нусратуллин и Р.Г. Хабибуллин проводят подробный анализ актуальных проблем управления муниципальным 
имуществом и предлагают программно-целевой подход как способ повышения эффективности использования объектов [12].

В.Э. Комовым исследованы факторы влияния внутренней и внешней среды на эффективность управления муниципальным имуществом и разработана схема процесса управления имуществом на примере одного из городов и муниципального района [9].

Для эффективного управления муниципальной собственностью требуется создание системы оценки управления объектами казны муниципального образования, акцентирующей внимание на проблемах территории с точки зрения распоряжения имуществом. Актуальными проблемами управления имуществом муниципалитетов являются наличие значительного количества бесхозяйных объектов, рост задолженности по арендной плате, неудовлетворительное физическое состояние объектов на балансе муниципального образования, не позволяющее эффективно использовать их в хозяйственном обороте [1-4].

Наблюдающаяся тенденция для многих муниципальных образований - активная продажа имущества (приватизация) - ведет к стремительному сокращению экономического потенциала муниципалитета. Полученные от продажи объектов муниципальной собственности доходы в текущем периоде позволяют решать некоторые задачи и проблемы территории. Но вместе с тем в будущих периодах муниципалитет лишается источников собственных доходов от использования проданных объектов (в виде доходов от предоставления объектов в аренду).

Эффективное управление определяется эффективным использованием и результативным управлением муниципальной собственностью. Под эффективностью использования муниципальной собственности понимается соотношение достигнутых результатов и использован- ных ресурсов муниципального образования. Результативность управления муниципальной собственностью - это степень достижения местными органами власти стратегических целей социально-экономического развития муниципального образования путем управленческого воздействия на объекты имущественного комплекса.

Авторами Т.Ю. Лушниковой и А.М. Ахатовой была предложена система показателей оценки эффективности управления муниципальным имуществом на примере одного из городов. Экономическая эффективность использования муниципальной собственности ими рассматривается как экономический эффект от управления - соотношение полученного бюджетом результата от управления муниципальной собственностью к общим затратам на управление [10].

Важной составляющей процесса повышения эффективности системы управления муниципальной собственностью является механизм выбора объектов имущества, подлежащих продаже и предоставлению в аренду в текущем периоде с целью максимизации доходов от управления объектами муниципального имуществ в перспективе.

Муниципалитетам предоставлено право самостоятельно разрабатывать методики и критерии оценки эффективности управления объектами имущества муниципального образования. Анализ подходов к оценке эффективности, имеющихся в различных муниципальных образованиях, показал, что используемые системы показателей не отражают наличие актуальных проблем управления муниципальным имуществом. В этой связи, автором была предложена система показателей оценки эффективности управления объектами недвижимого имущества муниципального образования, которая может являться основой разработки критериев - индикаторов для местных органов власти (табл. 1).

Таблица 1. Система показателей оценки эффективности управления объектами недвижимого имущества муниципального образования

\begin{tabular}{|c|c|c|}
\hline Показатель & Формула расчета & $\begin{array}{c}\text { Нормативное или оценоч- } \\
\text { ное значение }\end{array}$ \\
\hline $\begin{array}{l}\text { Показатель использова- } \\
\text { ния объектов недвижимого } \\
\text { имущества муниципального } \\
\text { образования }\end{array}$ & $\begin{array}{l}\text { Доля неиспользуемых площадей: } \\
N=\frac{S_{\text {общ }}-S_{\text {исп }}}{S_{\text {общ }}} * 100 \% \\
\mathrm{~S}_{\text {общ }}-\text { общая суммарная площадь всех объек- } \\
\text { тов недвижимого имущества муниципального } \\
\text { образования (нежилой фонд); } \\
\mathrm{S}_{\text {исп }- \text { площадь используемых (вовлеченных в }} \\
\text { хозяйственный оборот) объектов недвижимого } \\
\text { имущества муниципального образования }\end{array}$ & $\begin{array}{l}\text { При } \mathrm{N} \geqslant 20 \% \\
\text { уровень эффективности } \\
\text { использования объектов } \\
\text { недвижимости МО призна- } \\
\text { ется низким. }\end{array}$ \\
\hline
\end{tabular}




\begin{tabular}{|c|c|c|}
\hline $\begin{array}{l}\text { Показатель дебиторской } \\
\text { задолженности по договорам } \\
\text { аренды муниципального } \\
\text { имущества }\end{array}$ & $\begin{array}{l}\text { Доля дебиторской задолженности по категори- } \\
\text { ям арендаторов и их рискам: } \\
W_{i}=\frac{S_{i}}{\text { Дб }} * 100 \% \\
\mathrm{~W}_{\mathrm{i}}-\text { доли (удельные веса) дебиторской задол- } \\
\text { женности по договорам аренды муниципаль- } \\
\text { ной недвижимости по і-м категориям риска. } \\
\text { Дб = } S_{1}+S_{2}+S_{3} \\
\text { Дб - сумма дебиторской задолженности по } \\
\text { договорам аренды; } \\
\mathrm{S}_{1}-\text { сумма дебиторской задолженности арен- } \\
\text { даторов первой (низкой) группы риска; } \\
\mathrm{S}_{2}-\text { сумма дебиторской задолженности арен- } \\
\text { даторов второй (средней) группы риска; } \\
\mathrm{S}_{3}-\text { сумма дебиторской задолженности арен- } \\
\text { даторов третьей (высокой) группы риска }\end{array}$ & $\begin{array}{l}\text { Устанавливаются } \\
\text { требования: } \\
\left\{\begin{array}{l}W_{1} \geq 50 \% \\
W_{2} \leq 40 \% \\
W_{3} \leq 10 \%\end{array}\right. \\
\text { При несоблюдении требова- } \\
\text { ний уровень эффективности } \\
\text { управления признается } \\
\text { низким. Требуется измене- } \\
\text { ние структуры дебиторской } \\
\text { задолженности. }\end{array}$ \\
\hline $\begin{array}{l}\text { Показатель эксплуатационно- } \\
\text { го состояния объектов недви- } \\
\text { жимости (нежилого фонда) }\end{array}$ & $\begin{array}{l}\text { Показатель физического состояния объектов: } \\
\text { доля объектов в неудовлетворительном } \\
\text { техническом и эксплуатационном состоянии } \\
\text { (требуется капитальный/текущий ремонт): } \\
Q_{\text {неуд }}=\frac{S_{\text {неуд }}}{S_{\text {общ }}} * 100 \%\end{array}$ & $\begin{array}{l}\text { Устанавливается } \\
\text { требование: } \\
\mathrm{Q}_{\text {неуд }} \leqslant 20 \%\end{array}$ \\
\hline $\begin{array}{l}\text { Доля состоявшихся аукционов } \\
\text { по продаже объектов недви- } \\
\text { жимости }\end{array}$ & $\begin{array}{l}A_{\text {сост }}=\frac{Q_{\text {coсm }}}{Q_{\text {общ }}} * 100 \% \\
\underline{\mathrm{Q}}_{\text {сост }}-\text { количество состоявшихся аукционов; } \\
\mathrm{Q}_{\text {общ }}-\text { общее количество проводившихся } \\
\text { аукционов }\end{array}$ & $\begin{array}{l}\text { При А } \leqslant 80 \% \\
\text { уровень эффективности } \\
\text { проведения аукционов при- } \\
\text { знается низким. }\end{array}$ \\
\hline $\begin{array}{l}\text { Доходность управления } \\
\text { недвижимым имуществом } \\
\text { (объектами нежилого фонда) }\end{array}$ & 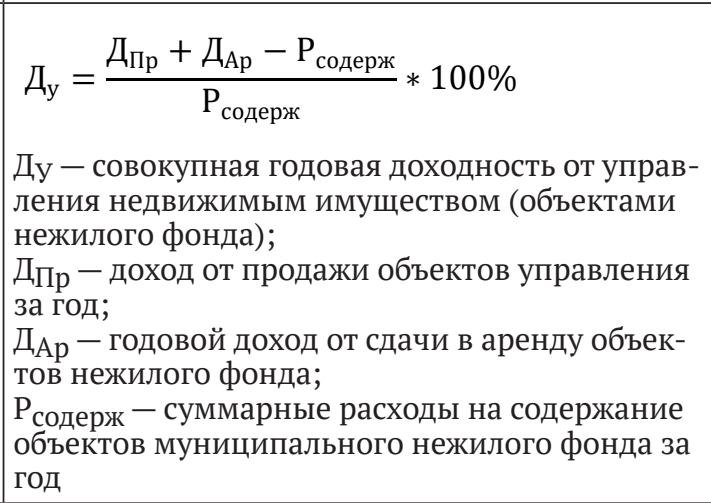 & $\begin{array}{l}\text { При Ду } \leqslant 10 \% \\
\text { уровень эффективности } \\
\text { использования объектов } \\
\text { недвижимости МО призна- } \\
\text { ется низким }\end{array}$ \\
\hline $\begin{array}{l}\text { Доля бесхозяйных объектов, } \\
\text { внесенных в реестр муни- } \\
\text { ципального имущества в } \\
\text { текущем году, от общего чис- } \\
\text { ла имеющихся бесхозяйных } \\
\text { объектов на балансе муници- } \\
\text { пального образования }\end{array}$ & $\begin{array}{l}Д_{\text {бесх.им. }}=\frac{Q_{\text {общ. }}}{Q_{\text {ми }}} * 100 \% \\
\text { Дбесх.им. - доля объектов, относящихся к } \\
\text { бесхозяйному имуществу, внесенных в реестр } \\
\text { муниципального имущества в текущем году; } \\
Q_{\text {общ. }}-\text { всего объектов, находящихся в рее- } \\
\text { стре бесхозяйных объектов на конец года; } \\
\text { Q }_{\text {ми - оформлено право муниципальной }} \\
\text { собственности на бесхозяйные объекты }\end{array}$ & $\begin{array}{l}\text { Устанавливается требова- } \\
\text { ние: } \\
\text { Дбесх.им. } \text { > 50\% }\end{array}$ \\
\hline
\end{tabular}

Составлено автором. 
Одной из основных задач управления муниципальным имуществом является повышение эффективности использования объектов недвижимости путем выбора между продажей и сдачей в аренду помещений, принадлежащих муниципальному образованию. Целью задачи повышения эффективности управления объектами муниципального имущества является получение максимального дохода от управления. Решение данной задачи автором предлагается осуществить на основе метода линейного программирования с использованием бинарных (булевых) переменных.

В комбинаторных задачах оптимизируется функция, заданная на конечном множестве, элементами которого служат выборки (перестановки) из $n$ объектов. При постановке комбинаторных задач в виде задач целочисленного математического программирования часто вводятся булевы переменные $x_{j} \in\{0,1\}$, носящие логический характер: $x_{j}=1$, если выполняется некоторое условие и $x_{j}=0$ в противном случае. Так, например, обстоит дело, когда решение сводится к выбору одного из возможных вариантов действий, включая и вариант отказа от каких бы то ни было действий.

Переменными значениями целевой функции является состав объектов муниципального имущества, т.е. на каждый период (год) управления определяется, какая часть объектов должна быть направлена на продажу, а какая часть объектов должна быть передана в аренду. Учитывая дискретный характер задаваемых переменных (каждый объект имущества может получать доход либо от передачи в аренду, либо от продажи, с момента продажи объекта, получение дохода от аренды невозможно), метод линейного программирования имеет некоторые ограничения при управлении объектами. Эти ограничения позволяет снять замена каждой целочисленной переменной булевыми (бинарными) переменными.

Постановка задачи осуществляется следующим образом:

- оценивается эффективность и целесообразность продажи/сдачи в аренду $n$ объектов муниципального имущества на начало периода управления;

- оценка и прогноз осуществляется на т периодов планирования (лет);

- стоимость продажи $i$-го объекта на начало планируемого периода $-P_{i}$;

- стоимость аренды $i$-го объекта на начало планируемого периода $-A_{i}$;

- стоимость содержания $i$-го объекта на начало планируемого периода $-C_{i}$.

Суммарный показатель доходов от управления объектами $D$ зависит от состава объектов, направленных на продажу, в аренду и находящихся на содержании муниципалитета, а также от стоимости і-го объекта продажи, аренды и содержания:

$$
D=f\left(x_{i j} ; P_{i j} ; A_{i j} ; C_{i j}\right)
$$

Доходы от продажи носят единовременный характер, т.е. объект за весь период управления может быть продан только один раз. Доходы от аренды носят постоянный характер, т.е. поступают в каждом периоде управления объектом до момента его продажи. С момента продажи доходы от аренды объекта невозможны.

Затраты на содержание объекта носят постоянный характер, т.е. поступают в каждом периоде управления объектом до момента его продажи. С момента продажи затраты на содержание объекта становятся равны нулю.

Требуется осуществить выбор объектов, направляемых на продажу или сдачу в аренду, с целью получения максимального дохода в бюджет муниципального образования.

Целевая функция имеет вид:

$$
\begin{aligned}
& D \rightarrow \max \\
& \sum_{i=1}^{n} \sum_{j=1}^{m} P_{i j}\left(1-x_{i j}\right)+\sum_{i=1}^{n} \sum_{j=1}^{m} x_{i j} *\left(A_{i j}-C_{i j}\right) \rightarrow \max
\end{aligned}
$$

$i=1 . . . n-$ количество объектов муниципального имущества, подвергающихся оценке при выборе между продажей и сдачей в аренду;

$j=1 . . . m-$ число лет оценки и прогноза.

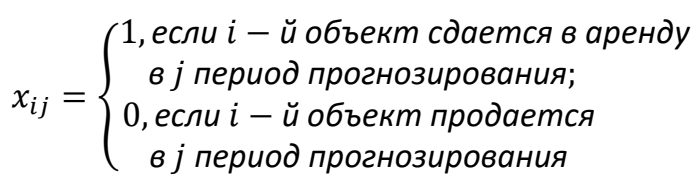

Расчеты производились на примере одного из городов Красноярского края. Объекты недвижимости поименованы как объект А, объект В, ... 
объект F.

Ограничения задаются в виде матриц оценки стоимости продажи, аренды и расходов на содержание объектов муниципального имущества:

- матрица стоимости продажи объектов муниципального имущества, где $p_{i j}$ - элемент матрицы - стоимость продажи $i$-го объекта в $j$-м периоде прогнозирования:

$P=\left(\begin{array}{ccccc}2861,0 & 2288,8 & 1945,5 & 1750,9 & 1663,4 \\ 4370,0 & 3496,0 & 2971,6 & 2674,4 & 2540,7 \\ 4959,0 & 3967,2 & 3372,1 & 3034,9 & 2883,2 \\ 5445,0 & 4356,0 & 3702,6 & 3332,3 & 3165,7 \\ 1334,0 & 1067,2 & 907,1 & 816,4 & 775,6 \\ 1208,0 & 966,4 & 821,4 & 739,3 & 702,3\end{array}\right)$

- матрица стоимости аренды объектов муниципального имущества, где $a_{i j}-$ элемент матрицы - стоимость аренды $i$-го объекта в $j$-м периоде прогнозирования:

$$
A=\left(\begin{array}{ccccc}
688,6 & 516,5 & 413,2 & 351,2 & 316,1 \\
2304,3 & 1728,2 & 1382,6 & 1175,2 & 1057,7 \\
1242,7 & 932,0 & 745,6 & 633,8 & 570,4 \\
600,6 & 450,5 & 360,4 & 306,3 & 275,7 \\
375,5 & 281,6 & 225,3 & 191,5 & 172,4 \\
769,0 & 576,7 & 461,4 & 392,2 & 353,0
\end{array}\right)
$$

- матрица стоимости содержания объектов муниципального имущества, где $c_{i j}$ - элемент матрицы - стоимость содержания $i$-го объекта в j-м периоде прогнозирования:

$$
\mathrm{C}=\left(\begin{array}{ccccc}
65,7 & 69,0 & 75,9 & 87,3 & 104,8 \\
219,4 & 230,4 & 253,4 & 291,5 & 349,7 \\
118,3 & 124,3 & 136,7 & 157,2 & 188,6 \\
57,2 & 60,1 & 66,1 & 76,0 & 91,2 \\
35,8 & 37,5 & 41,3 & 47,5 & 57,0 \\
73,2 & 76,9 & 84,6 & 97,3 & 116,7
\end{array}\right)
$$

Оценка доходов и расходов от управления объектами осуществляется по формуле:

$$
S_{i}=P_{i j} *\left(1-x_{i j}\right)+x_{i j} *\left(A_{i j}-C_{i j}\right)
$$

где $P_{i j}$ - стоимость продажи $i$-го объекта в $j$-м периоде прогнозирования;

$A_{i}-$ стоимость аренды $i$-го объекта в $j$-м периоде прогнозирования;

$C_{i}-$ стоимость содержания $i$-го объекта в $j-\mathrm{M}$ периоде прогнозирования;

$x_{i j}$ - искомая бинарная переменная (0 - продажа или 1 - сдача в аренду для $i$-го объекта в $j$-м периоде прогнозирования);

$i=1 . . . n-$ объект муниципального имущества, подвергающийся оценке при выборе между продажей и сдачей в аренду;

$j=1 . . . m-$ период оценки и прогноза.

Решение задачи осуществлялось с помощью функции «Поиск решения» в Microsoft Office Excel (встроенный метод решения - метод Ньютона) при $n=6 ; m=5$. Расчет показателей оценки совокупного дохода от управления объектами приведен в таблице 2.

Описанным выше методом было получено решение и представлено в таблице 3.

Таким образом, оптимальный план по управлению выбранными объектами муниципального имущества выглядит следующим образом:

- объект А следует продать в первый год планирования;

- объект В следует сдавать в аренду четыре года прогнозного периода, в пятый год - продать;

- объект C следует сдавать в аренду три первых прогнозных периода и продать на четвертый год;

- объект D следует продать в первый прогнозный период (год);

- объект Е следует сдавать в аренду первые два года, в третий год - продать;

- объект F должен быть продан в пятый год прогнозного периода.

Далее был рассчитан совокупный доход от управления выбранными объектами муниципального имущества за прогнозный период (5 лет) в рамках полученного решения и достижения максимума целевой функции равен 23012,61 тыс. руб.

Таким образом, на основании предложенного методического подхода к оптимизации структуры муниципального имущества стоит говорить о том, что подобная модель адекватна и ее дальнейшее использование позволит департаменту муниципального имущества и земельных отношений города подбирать оптимальный вариант использования объектов нежилого фонда с целью получения наибольшего денежного дохода.

Комплексный подход к рассмотрению проблем управления муниципальным имуществом необходим для эффективного решения вопросов местного значения и развития социально-экономического потенциала территории. 
Таблица 2. Расчет показателей для оценки совокупного дохода от управления объектами недвижимости муниципального образования

\begin{tabular}{|c|c|c|c|c|c|}
\hline Показатель & 1-й год & 2-й год & 3-й год & 4-й год & 5-й год \\
\hline Совокупный доход за год $=\mathrm{S}_{\mathrm{a}}+\mathrm{S}_{\mathrm{b}}+\mathrm{S}_{\mathrm{c}}+\mathrm{S}_{\mathrm{d}}+\mathrm{S}_{\mathrm{e}}+\mathrm{S}_{\mathrm{f}}$ & 10604,5 & 4070,6 & 3221,6 & 2845,7 & 2270,1 \\
\hline $\begin{array}{l}\text { Оценка доходов и расходов от управления объектом } A \\
S_{a}=P_{a j}{ }^{*}\left(1-x_{a j}\right)+x_{a j}{ }^{*}\left(A_{a j}-C_{a j}\right)\end{array}$ & 877,8 & 602,8 & 445,1 & 332,5 & 228,8 \\
\hline Площадь объекта А в управлении на начало периода (кв. м.) & \multicolumn{5}{|c|}{161,2} \\
\hline Стоимость продажи объекта (Р) тыс. руб. & 2861 & 2288,8 & 1945,5 & 1750,9 & 1663,4 \\
\hline Стоимость аренды объекта (А) тыс. руб. & 688,6 & 516,5 & 413,2 & 351,2 & 316,1 \\
\hline Стоимость содержания объекта (C) тыс. руб. & 65,7 & 69,0 & 75,9 & 87,3 & 104,8 \\
\hline $\begin{array}{l}\text { Оценка доходов и расходов от управления объектом } B \\
S_{b}=P_{b j} *\left(1-x_{b j}\right)+x_{b j}{ }^{*}\left(A_{b j}-C_{b j}\right)\end{array}$ & 2084,9 & 1497,8 & 1129,2 & 1212,8 & 1129,4 \\
\hline Площадь объекта В в управлении на начало периода (кв. м.) & \multicolumn{5}{|c|}{539,4} \\
\hline Стоимость продажи объекта (Р) тыс. руб. & 4370 & 3496 & 2971,6 & 2674,4 & 2540,7 \\
\hline Стоимость аренды объекта (А) тыс. руб. & 2304,3 & 1728,2 & 1382,6 & 1175,2 & 1057,7 \\
\hline Стоимость содержания объекта (C) тыс. руб. & 219,4 & 230,4 & 253,4 & 291,5 & 349,7 \\
\hline $\begin{array}{l}\text { Оценка доходов и расходов от управления объектом } C \\
S_{C}=P_{c j}{ }^{*}\left(1-x_{c j}\right)+x_{c j} *\left(A_{c j}-C_{c j}\right)\end{array}$ & 1124,4 & 1187,1 & 1052,8 & 813,3 & 499,9 \\
\hline Площадь объекта С в управлении на начало периода (кв. м.) & \multicolumn{5}{|c|}{290,9} \\
\hline Стоимость продажи объекта (Р) тыс. руб. & 4959 & 3967,2 & 3372,1 & 3034,9 & 2883,2 \\
\hline Стоимость аренды объекта (А) тыс. руб. & 1242,7 & 932,0 & 745,6 & 633,8 & 570,4 \\
\hline Стоимость содержания объекта (C) тыс. руб. & 118,3 & 124,3 & 136,7 & 157,2 & 188,6 \\
\hline $\begin{array}{l}\text { Оценка доходов и расходов от управления объектом } D \\
S_{d}=P_{d j} *\left(1-x_{d j}\right)+x_{d j} *\left(A_{d j}-C_{d j}\right)\end{array}$ & 5435,9 & 0,7 & 0,5 & 0,4 & 0,4 \\
\hline Площадь объекта D в управлении на начало периода (кв. м.) & \multicolumn{5}{|c|}{140,6} \\
\hline Стоимость продажи объекта (Р) тыс. руб. & 5445 & 4356 & 3702,6 & 3332,3 & 3165,7 \\
\hline Стоимость аренды объекта (А) тыс. руб. & 600,6 & 450,5 & 360,4 & 306,3 & 275,7 \\
\hline Стоимость содержания объекта (C) тыс. руб. & 57,2 & 60,1 & 66,1 & 76,0 & 91,2 \\
\hline $\begin{array}{l}\text { Оценкка доходов и расходов от управления объектом } E \\
S_{e}=P_{e j} *\left(1-x_{e j}\right)+x_{e j} *\left(A_{e j}-C_{e j}\right)\end{array}$ & 385,8 & 282,3 & 217,2 & 173,1 & 140,7 \\
\hline Площадь объекта Е в управлении на начало периода (кв. м.) & \multicolumn{5}{|c|}{87,9} \\
\hline Стоимость продажи объекта (Р) тыс. руб. & 1334 & 1067,2 & 907,1 & 816,4 & 775,6 \\
\hline Стоимость аренды объекта (А) тыс. руб. & 375,5 & 281,6 & 225,3 & 191,5 & 172,4 \\
\hline Стоимость содержания объекта (C) тыс. руб. & 35,76 & 37,55 & 41,30 & 47,50 & 56,99 \\
\hline $\begin{array}{l}\text { Оценка доходов и расходов от управления объектом } F \\
S_{f}=P_{f j} *\left(1-x_{f j}\right)+x_{f j} *\left(A_{f j}-C_{f j}\right)\end{array}$ & 695,7 & 499,8 & 376,8 & 313,6 & 271,0 \\
\hline Площадь объекта F в управлении на начало периода (кв. м.) & \multicolumn{5}{|c|}{180} \\
\hline Стоимость продажи объекта (Р) тыс. руб. & 1208 & 966,4 & 821,4 & 739,3 & 702,3 \\
\hline Стоимость аренды объекта (А) тыс. руб. & 769,0 & 576,7 & 461,4 & 392,2 & 353,0 \\
\hline Стоимость содержания объекта (С) тыс. руб. & 73,2 & 76,9 & 84,6 & 97,3 & 116,7 \\
\hline $\begin{array}{l}\text { Целевая функция: максимизация доходов от управления } \\
\text { имуществом (тыс. руб.) - рассчитано после получения реше- } \\
\text { ния }\end{array}$ & \multicolumn{4}{|c|}{ Итого: } & 23012,61 \\
\hline
\end{tabular}

Составлено автором. 
Таблица 3 - Оценка искомых переменных - альтернатив между продажей и сдачей в аренду объектов муниципального имущества с целью максимизации доходов

\begin{tabular}{|l|c|c|c|c|c|}
\hline \multirow{2}{*}{ Объект муниципального имущества } & $x_{i 1}$ & $x_{i 2}$ & $x_{i 3}$ & $x_{i 4}$ & $x_{i 5}$ \\
\cline { 2 - 6 } & 1 -й год & 2 -й год & 3-й год & 4 -й год & 5 -й год \\
\hline Объект A & 0 & 0 & 0 & 0 & 0 \\
\hline Объект B & 1 & 1 & 1 & 1 & 0 \\
\hline Объект C & 1 & 1 & 1 & 0 & 0 \\
\hline Объект D & 0 & 0 & 0 & 0 & 0 \\
\hline Объект E & 1 & 1 & 0 & 0 & 0 \\
\hline Объект F & 1 & 1 & 1 & 1 & 0 \\
\hline
\end{tabular}

В таблице:

1 - объект должен сдаваться в аренду в данном периоде;

0 - объект должен быть продан в данном периоде - с целью максимизации доходов от управления.

Составлено автором.

В результате выполнения мероприятий по совершенствованию системы управления муниципальным имуществом в соответствии с предложенными рекомендациями может быть создан сбалансированный подход к оценке эффективности деятельности местных органов власти в сфере управления собственностью муниципалитета.
Разработанная система показателей оценки эффективности управления муниципальным имуществом, учитывающая значимые параметры системы, а также подход к построению оптимальной структуры муниципальной собственности выступают инструментами формирования мероприятий органов власти, направленных на решение проблем муниципалитета.

\section{Библиографический список}

1. Абазова Л.Х. Проблемы оценки эффективности управления государственной собственностью и меры по ее повышению // Актуальные вопросы экономических наук. 2016. № 3. С. 8-11.

2. Бабун Р. В. Современные проблемы управления земельно-имущественными комплексами муниципальных образований // Имущественные отношения в РФ. 2013. № 9 (144). С. 34-38.

3. Байдаков А. Н., Максимов В.Ю., Мирошниченко Н.В., Назаренко А.В. Правовые, экономические и социальные проблемы эффективного управления государственным и муниципальным имуществом // Экономика и управление: проблемы, решения. 2019. Т. 2. № 3. С. 4-9.

4. Бокаев А.В. Проблемы и пути формирования и эффективного использования муниципальной собственности // Известия ИГЭА. 2011. № 5. С. 44-46.

5. Бутов В.Н. Управление имуществом муниципального образования: вопросы теории и практики // Вестник Южно-Уральского государственного университета. 2012. № 7 (266). С. 78-81.

6. Загриев А.Р. Факторы повышения эффективности управления объектами муниципального имущества // Science Time. 2019. № 5 (65). C. 23-28.

7. Карасев О.Ю. Зарубежный опыт управления муниципальным имуществом // Право и современные государства. 2013. № 1. С. 16-23.

8. Козлова Е. Д., Ермолаев Д.В. Имущественный комплекс муниципального образования как экономическая основа местного самоуправления // Известия Тульского государственного университета. 2016. № 1. С. 2-6.

9. Комов В.Э. Влияние факторов внутренней и внешней среды на эффективность управления муниципальным имуществом // Известия Тульского государственного университета. 2015. № 1(1). С. 140-147.

10. Лушникова Т. Ю., Ахатова А.М. Об оценке эффективности управления муниципальным имуществом // Вестник Челябинского государственного университета. 2015. № 1 (356). С. 22-30.

11. Лыскова Н.А. Совершенствование управления муниципальной собственностью как условие реализации муниципальных экономических интересов // Пространство экономики. 2010. № 3 (2). С. 213-219.

12. Мусин У.Р., Нусратуллин И.В., Хабибуллин Р.Г. Управление муниципальным имуществом: программно-целевой подход // Московский экономический журнал. 2019. № 1. С. 500-504.

13. Попов А.С., Гандзюк Е.В. Методы управления недвижимыми активами муниципальных образований // Имущественные отношения в РФ. 2011. № 7. С. 28-43. 
14. Пригожин В.Л., Огнев Д.В. Инновационные направления совершенствования управления муниципальной собственностью // Современные исследования социальных проблем. 2012. № 1. С. 338-347.

15. Труфанова С.А. Анализ применения концепции стоимостного подхода к совершенствованию системы управления муниципальной недвижимостью // Имущественные отношения в РФ. 2013. № 3 (138). С. $91-102$.

16. Филатова Н.Г. Эффективное управление муниципальной собственностью как условие социально-экономического развития муниципального образования // Муниципальная экономика. 2011. № 2 (46). С. 48-58.

17. Хакимов В.В. Особенности системы управления муниципальной собственностью // Вестник Челябинского государственного университета. 2016. № 2 (384). С. 214-221.

18. Чудинов С.А. Управление муниципальной собственностью: проблемы и пути совершенствования // Вестник Саратовского государственного социально-экономического университета. 2013. № 2. С. 74-78.

19. Ялялиева Т. В. К проблеме эффективности управления муниципальной собственностью // Научный журнал Кубанского государственного аграрного университета. 2013. № 90.

20. Ямщикова И. В., Боброва Е.Ю. Теоретические основы управления муниципальной собственностью // Известия вузов. Инвестиции. Строительство. Недвижимость. 2016. № 2 (17). С. 112-119. 